\title{
NEUROCUTANEOUS SYNDROMES AND RETROPERITONEAL TUMORS
}

\author{
RICARDO ROSSI, M.D. \\ JOHN A. LIBERTINO, M.D. \\ JOSEPH B. DOWD, M.D. \\ JOHN W. BRAASCH, M.D.
}

From the Departments of Urology and Surgery, Lahey Clinic Foundation, Boston, Massachusetts

\begin{abstract}
A patient with multiple basal cell carcinoma syndrome, a symptom complex characteristized by nevoid basal cell carcinomas of the skin, jaw cysts, skeletal abnormalities, and hyporesponsiveness to parathormone is presented. In addition, the patient had a retroperitoneal lymphangiomyoma, a hamartomatous lesion, causing ureteral obstruction. The association of neuroectodermic syndromes and retroperitoneal and intra-abdominal tumors is reviewed.
\end{abstract}

Lymphangiomyomatosis occurs rarely. It is considered a hamartomatous lesion, usually involving lungs and lymph nodes and occasionally affecting isolated extrapulmonary lymphatics. We recently treated a patient with multiple basal cell carcinoma syndrome, a symptom complex characterized by hamartomas of the skin, cysts of the jaw, skeletal abnormalities, and hyporesponsiveness to parathormone. In addition, a retroperitoneal lymphangiomyoma was present that resulted in sequential bilateral ureteral obstruction, hypertension, and loss of one kidney.

\section{Case Report}

A forty-two-year-old woman with multiple basal cell carcinoma syndrome was seen in 1959 because of increased abdominal girth (Fig. 1A). At that time she underwent marsupialization of an abdominal chylous cyst. In 1960, she had a partial resection of the retroperitoneal chylous tumor, which was compressing the left ureter (Fig. 1B). In 1967, she required a left nephrectomy for severe hypertension, hydronephrosis, and pyelonephritis. Ten years later she was referred to Lahey Clinic for persistent epigastric and intermittent abdominal pain on her left side. Intravenous pyelography revealed calicectasis and anterolateral deviation of the solitary right kidney and ureter (Fig. 1C). Abdominal echography disclosed a large cystic retroperitoneal mass. Aortography demonstrated a tumor with neovascularity that extended to both sides of the midline (Fig. 1D). On venography, the vena cava appeared obstructed with drainage through enlarged lumbar veins into the left hemiazygos system (Fig. 1E). Retroperitoneal distortion of the stomach was seen on radiographs after an upper gastrointestinal barium series. Serum creatinine was $1 \mathrm{mg} . / 100 \mathrm{ml}$. and creatinine clearance, $51 \mathrm{ml}$. per minute.

Operation revealed a large, multicystic retroperitoneal tumor containing chyle located mainly in the right retroperitoneum but extending into both flanks. Two long iliac veins were joined $1 \mathrm{~cm}$. below the right renal vein. The tumor was adherent to the aorta and pushed these iliac veins ventrally, encircling them and the right renal pedicle. Resection of the tumor was accomplished with preservation of the patient's solitary kidney. The postoperative course was uneventful and recovery prompt. Histologic examination of the resected retroperitoneal tumor revealed a lymphangiomyoma. 

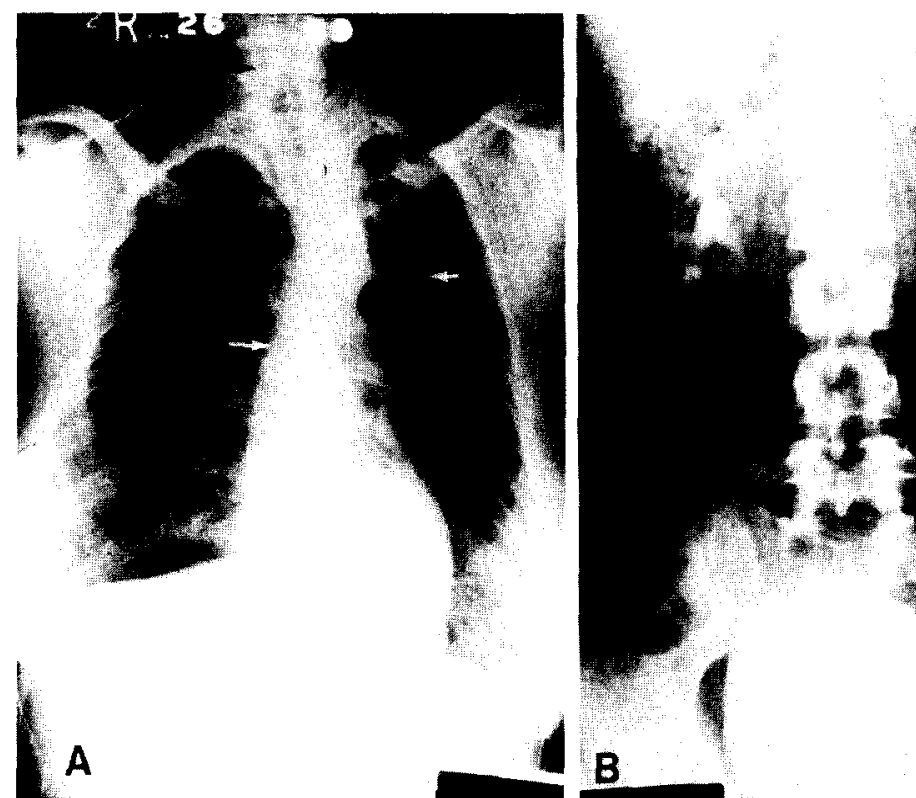

A

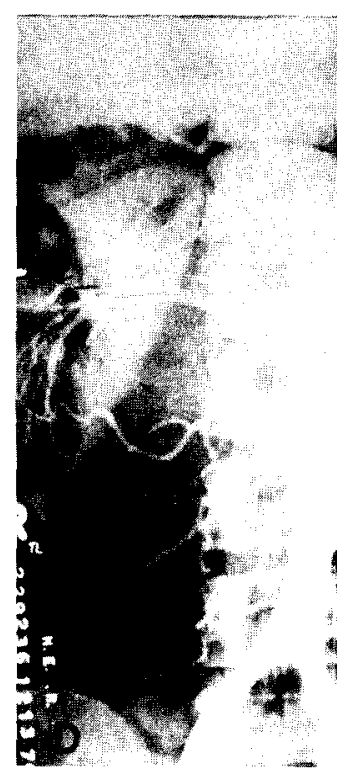

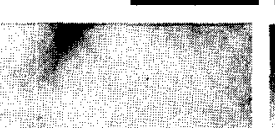
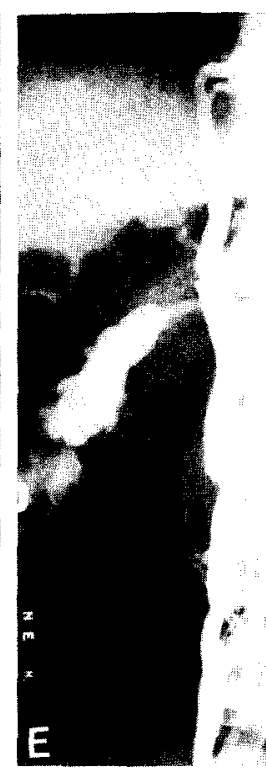

\section{Comment}

Primary retroperitoneal tumors cause ureteral displacement with or without obstruction in 60 per cent of patients. Most of these tumors are malignant (77 to 87 per cent); lymphomas and fibrosarcomas are the most common., 1,2

Lymphangiomyomas are rare and have been considered hamartomas characterized by proliferation of smooth muscle fascicles divided from each other by lymphatic channels. ${ }^{3}$ They involve major lymphatic trunks of mediastinum and retroperitoneum, lymph nodes, and lungs, often in a multifocal distribution.

In 1973, Wolff ${ }^{3}$ reviewed the literature and found 30 lymphangiomyomas; all of the patients were women, with an average age of forty years. Most tumors were intrathoracic, either presenting as a localized process or as a diffuse pulmonary involvement, including honeycomb lung and pulmonary insufficiency. Only seven tumors were confined to the retroperitoneum, and 9 patients had simultaneous involvement of retroperitoneum and thorax or inguinal nodes. Association with pleural or peritoneal chylous effisions was common. Abdominal enlargement has been the main feature on presentation. Chyluria has been reported in 1 case. ${ }^{4}$

In addition to intravenous pyelography, cavography, aortography, and ultrasonography, lymphangiography has been used in evaluation of retroperitoneal lymphangiomyomas. ${ }^{3-5}$ For 
localized mediastinal and retroperitoneal lesions, surgical excision is the preferred treatment and achieves good results. ${ }^{3-6}$ Radiotherapy has been used with no clear success. ${ }^{6}$

Concomitant lymphangiomyoma and tuberous sclerosis, an entity with multiple organ hamartomas, have been reported and the relationship of its pulmonary and renal lesions reviewed. ${ }^{3,7,8}$ Monteforte and Kohnen ${ }^{9}$ reported an incidence of renal angiomyolipomas of 80 per cent in tuberous sclerosis and of 15 per cent in lymphangiomyomas. Uterine leiomyomas have also been described in both entities.

The multiple nevi basal cell carcinoma syndrome is an inherited autosomal syndrome characterized by multiple nevoid basal cell carcinomas of the skin, cysts of the jaw, skeletal abnormalities, and hyporesponsiveness to parathormone. ${ }^{10}$ It has been associated with medulloblastomas, ${ }^{10}$ mesenteric cysts, and fibromas of the ovary. ${ }^{11}$

The surgeon dealing with retroperitoneal disease should be aware of these different neuroectodermic syndromes and their possible association with different intra-abdominal and retroperitoneal tumors.

Boston, Massachusetts 02215

(DR. LIBERTINO)
ACKnowledgment. To Robert Kane, M.D., for radiologic evaluation, and William A. Meissner, M.D., and Desiree Carlson, M.D., for review of the histologic slides.

\section{References}

1. Braasch JW, and Mon AB: Primary retroperitoneal tumors, Surg. Clin. North Am. 47: 663 (1967).

2. Jacobsen S, and Juul-Jorgensen S: Primary retroperitoneal tumours. A review of 26 cases, Acta Chir. Scand. 140: 498 (1974).

3. Wolf M: Lymphangiomyoma: clinicopathologic study and ultrastructural confirmation of its histogenesis, Cancer 31: 988 (1973).

4. Gray SR, Carrington CB, and Cornog JL, Jr: Lymphangiomyomatosis: report of a case with ureteral involvement and chyluria, ibid. 35: 490 (1975).

5. Cavina C, Marini G, and Scarpelli PT: Ascite chilosa da angiopericitoma retroperitoneale (aspetti anatomo-clinici e linfografici), Nunt Radiul. 32: 181 (1966).

6. Silverstein EF, et al: Pulmonary lymphangiomyomatosis, Am. J. Roentgenol. Radium Ther. Nucl. Med. 120: 832 (1974).

7. Jao J, Gilbert S, and Messer R: Lymphangiomyoma and tuberous sclerosis, Cancer 29: 1188 (1972).

8. Hickey BB, et al: Renal and pulmonary tuberose sclerosis: the relationship of the renal lesion to haemangiopericytoma, $\mathrm{Br}$. J. Surg. 49: 396 (1962).

9. Monteforte W], Jr, and Kohnen PW: Angiomyolipomas in a case of lymphangiomyomatosis syndrome: relationships to tuberous sclerosis, Cancer 34: 317 (1974).

10. Gorlin RJ, et al: Multiple basal-cell nevi syndrome, an analysis of a syndrome consisting of multiple nevoid basal-cell carcinoma, jaw cysts, skeletal anomalies, medulloblastoma, and hyporesponsiveness to parathormone, ibid. 18: 89 (1965).

11. Clendenning WE, Herdt JR, and Block JB: Ovarian fibromas and mesenteric cysts: their association with hereditary basal cell carcinoma of the skin, Am. J. Obstet. Gynecol. 87: 1008 (1963). 